University of Nebraska - Lincoln

DigitalCommons@University of Nebraska - Lincoln

Publications, Agencies and Staff of the U.S.

Department of Commerce

U.S. Department of Commerce

2005

Fatigue Sensitivity of Y-TZP to Microscale Sharp-Contact Flaws

Yu Zhang

New York University College of Dentistry

Brian R. Lawn

National Institute of Standards and Technology, brian.lawn@nist.gov

Follow this and additional works at: https://digitalcommons.unl.edu/usdeptcommercepub

Part of the Environmental Sciences Commons

Zhang, Yu and Lawn, Brian R., "Fatigue Sensitivity of Y-TZP to Microscale Sharp-Contact Flaws" (2005). Publications, Agencies and Staff of the U.S. Department of Commerce. 53.

https://digitalcommons.unl.edu/usdeptcommercepub/53

This Article is brought to you for free and open access by the U.S. Department of Commerce at DigitalCommons@University of Nebraska - Lincoln. It has been accepted for inclusion in Publications, Agencies and Staff of the U.S. Department of Commerce by an authorized administrator of DigitalCommons@University of Nebraska - Lincoln. 


\title{
Fatigue Sensitivity of Y-TZP to Microscale Sharp-Contact Flaws
}

\author{
Yu Zhang, ${ }^{1}$ Brian R. Lawn ${ }^{2}$ \\ ${ }^{1}$ New York University College of Dentistry, 345 East 24th Street, New York, New York 10010 \\ ${ }^{2}$ Materials Science and Engineering Laboratory, National Institute of Standards and Technology, \\ Gaithersburg, Maryland 20899-8500
}

Received 28 May 2004; accepted 13 August 2004

Published online 18 November 2004 in Wiley InterScience (www.interscience.wiley.com). DOI: 10.1002/jbm.b.30174

\begin{abstract}
The strength degrading effects of sharp-contact damage are examined for Y-TZP ceramic plates bonded to a plastic substrate. Contacts are made with Vickers and Berkovich diamond indenters at low loads $(0.1 N$ to $100 N)$ in the ceramic lower surfaces prior to bonding to the substrates. The indentations remain in the subthreshold region, that is, without visible corner radial cracks, over the lower region $(<10 \mathrm{~N})$ of the load range. A concentrated load is then applied sinusoidally to the ceramic upper surface, with the loading axis centered on the subsurface indentation flaw, thereby subjecting the flaw to cyclic tension. Relative to polished surfaces, the indentations diminish the single-cycle strength by an amount that increases with increasing indentation load. The critical number of cycles required to cause failure from the indentation flaws is then measured at specified maximum lower surface tensile stresses. At each indentation load, the strength of the ceramic plates diminishes with increased cycling. The scale of degradation is compared with that from previous studies on Y-TZP surfaces containing larger-scale surface damage: sandblast damage, as used in dental crown preparation; and blunt-contact trauma from a spherical indenter at $3000 \mathrm{~N}$. These other damage modes are shown to be equivalent in their strength-degrading capacity to diamond pyramid indentations in the microscale load range $0.1 N$ to $1 N$, attesting to the highly deleterious nature of sharp particulate contacts. The mechanism of fatigue is considered in terms of microcrack evolution within the indentation damage zone. () 2004 Wiley Periodicals, Inc.* J Biomed Mater Res Part B: Appl Biomater 72B: 388-392, 2005
\end{abstract}

Keywords: biomechanical ceramics; cyclic fatigue; microcracks; sharp contacts

\section{INTRODUCTION}

The fatigue of ceramic materials containing surface damage from surface contact loading can be severe, due in large part to intense stresses generated at the damage sites. ${ }^{1-18}$ Such stresses can in turn generate microcracks within the damage zone - and, under severe conditions, these microcracks can coalesce into dangerous radial macrocracks extending beyond the zone boundaries. Damage accumulation of this kind becomes a major concern in the design of ceramics for longlifetime biomechanical applications, for example, in all-ceramic crowns for dental restorations and ceramic liners for acetabular cups in total hip replacements. ${ }^{19,20}$ Contacts from blunt instruments or sharp particulates during preparation or

Information on product names and suppliers in this paper is not to imply endorsement by NIST.

Correspondence to: Brian R. Lawn, Materials Science and Engineering Laboratory, National Institute of Standards and Technology, Bldg. 223, Room B309, 100 Bureau Drive, Gaithersburg, MD 20899-8500 (e-mail: brian.lawn@nist.gov)

Contract grant sponsor: National Institute of Dental and Craniofacial Research; contract grant number: PO1 DE10976

(C) 2004 Wiley Periodicals, Inc. *This article is a US Government work and, as such, is in the public domain in the United States of America. insertion of a prosthesis can be effective sources of such damage; continued damage evolution during subsequent function can then lead to premature failure of the prosthesis. In the context of fatigue fracture, where the initial microcracks may be not much larger than the scale of the ceramic microstructure, this is known as the short-crack domain. ${ }^{21}$

One ceramic that continues to generate great interest in biomechanical applications, at least in dental crowns, is yttria-tetragonal-zirconia polycrystal (Y-TZP), primarily for its high strength. In dental crowns, the ceramic layer is supported by underlying tooth dentin, which is relatively compliant and allows the crown to flex repeatedly during biting contacts from the opposing tooth at the occlusal surface. ${ }^{22,23}$ Tensile stresses from the flexure can then lead to formation of large radial cracks at the ceramic lower surface. These interface-initiated radial cracks are especially dangerous in layer configurations with brittle components. ${ }^{16,22-24}$ Fatigue studies of Y-TZP plates bonded onto polymer support substrates, in simulation of the basic crown configuration, have previously been carried out on plates in the as-polished state and after blunt-indenter and sandblast damage. ${ }^{17,18,25}$ There, fatigue was attributed in part to slow growth of pre- 
cursor microcracks within the imposed damage zones under the continually imposed stresses - and, in the case of contact-induced damage, to some additional mechanical degradation at back-and-forth sliding microcrack surfaces - prior to macroscopic radial cracking.

In the present study, an examination is made of the flexural response of Y-TZP specimens containing small-scale flaws introduced by sharp diamond indenters. Sharp indenters usefully simulate the damage patterns encountered from contacts with hard particulates in surface machining, sandblasting, and scratching. The damage is readily controlled and quantified via the indentation load. The intense elastic-plastic stress fields associated with sharp indentations produce well-developed radial cracks down to microscale loads in most ceramics. ${ }^{1,26}$ It will be demonstrated that even micrometer scale indentations below which any visible radial cracking occurs can lead to high loss in material strength in Y-TZP, far greater than from comparable blunt contacts. ${ }^{17,18,25}$ These results will attest to the need for extreme caution in crown preparation, especially from sharp contacts.

\section{EXPERIMENTAL}

Specimens from the same batch of medical grade $3 \mathrm{~mol} \%$ Y-TZP (Prozyr, Norton, East Granby, CT) as used in previous studies ${ }^{17,18,25,27,28}$ were prepared as plates $20 \mathrm{~mm} \times 20$ $\mathrm{mm} \times 0.6 \mathrm{~mm}$. This material had an equiaxed microstructure of mean grain size about $0.5 \mu \mathrm{m}$. Surfaces were polished with diamond paste to $1 \mu \mathrm{m}$ finish. X-ray diffraction analysis indicated near-zero monoclinic phase on these surfaces.

Single-cycle Vickers microindentations (Zwick 3212, Zwick USA, Kennesaw, GA) and Berkovich nanoindentations (Nanoindenter XP, MTS Systems Corp., Oakridge, TN) were placed at the centers of the Y-TZP plates. The load ranges for each instrument were $P=0.1 N$ to $1 N$ (Berkovich) and $1 N$ to $100 N$ (Vickers). The plates were then inverted with the indentation face downward and bonded with a thin layer $(\sim 10 \mu \mathrm{m})$ of epoxy resin to polycarbonate support layers $12.5 \mathrm{~mm}$ thick (Figure 1). Some plates were bonded without indentation as damage-free controls.

The plates were placed on a specimen stage of a mechanical testing machine (Instron 8500, Instron Corp., Boston, MA) and slightly preloaded $(\sim 3 N)$ with a tungsten carbide sphere of radius $3.18 \mathrm{~mm}$. A video camera system with a $45^{\circ}$ mirror located immediately below a small hole in the stage facilitated initial alignment of the indentation sites with the load axis. ${ }^{29}$ The specimen was then cycled sinusoidally between the preload and prescribed maximum load at frequency $f=10 \mathrm{~Hz}$, and visually monitored via the video recording system until failure occurred from the generation of largescale radial cracks at the ceramic bottom surface. The critical numbers of cycles $n$ to failure for prescribed maximum loads were thus measured. The tensile stress at the bottom of the ceramic surface was calculated from the maximum sphere load $L$ using the bilayer relation $S=\left(L / B d^{2}\right) \log \left(E_{\mathrm{c}} / E_{\mathrm{s}}\right)$, with ceramic modulus $E_{\mathrm{c}}=205 \mathrm{GPa}$ for Y-TZP, substrate mod-

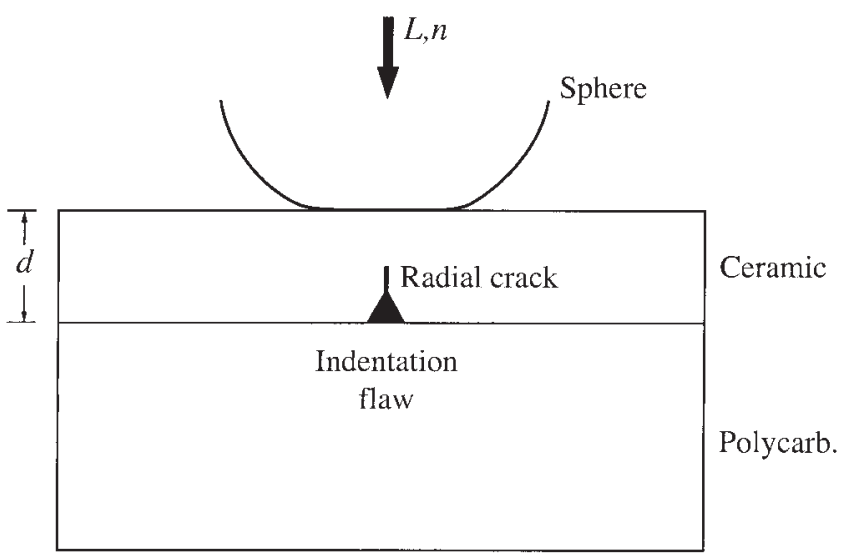

Figure 1. Schematic of bilayer strength test for ceramic specimen containing indentation flaw, load $P$, at lower surface. Bilayer is subjected to flexure over $n$ cycles from sphere at load $L$ at top surface.

ulus $E_{\mathrm{s}}=2.3 \mathrm{GPa}$ for polycarbonate, and $B=1.35 \mathrm{a}$ dimensionless constant. ${ }^{30}$

Special care was taken to confirm the source of fracture, for example, indentation site or otherwise. The indentation sites were examined for any associated corner cracking, before and after cycling. In the latter case, the Y-TZP plate was detached from the polycarbonate substrate and cleaned in acetone before observation in an atomic force microscope (Digital Instruments Nanoscope IIIa, Veeco Metrology, Santa Barbara, CA).

\section{RESULTS}

Examination of indentation sites before and after cyclic loading of the Y-TZP bilayer specimens revealed relatively immature development of corner radial cracks over the load range $P=0.1 N$ to $10 N .^{31,32}$ Prior to cycling, fully developed radial cracks (i.e., crack size $>$ twice indentation half-diagonal) were evident at $P=100 \mathrm{~N}$, but these progressively diminished in scale to miniscule corner cracks at $20 \mathrm{~N}$. No corner cracking was evident at lower loads. At slightly lower loads, small corner cracks began to appear at indentations which showed none prior to cycling. An example of the latter is shown in Figure 2, for an indentation at $P=10 \mathrm{~N}$ after $n=$ $1.7 \times 10^{5}$ cycles, corresponding to a failure strength $S=597$ MPa. In this case, specimen failure has occurred from two opposite corners (arrows), with small cracks at the remaining corners (circles). For loads at $P=1 N$ or lower, visible corner cracks never appeared either prior to or after cyclic failure. Nevertheless, failures still occurred at these sites. These results indicate that failure is occurring in the subthreshold indentation region, that is, from within the indentation quasiplastic damage zone, over most of the load range of interest here.

Figure 3 plots single-cycle strength $S$ as a function of indentation load $P$. Filled data points from $P=100 \mathrm{~N}$ down to $1 \mathrm{~N}$ represent breaks from indentation sites. Unfilled data 


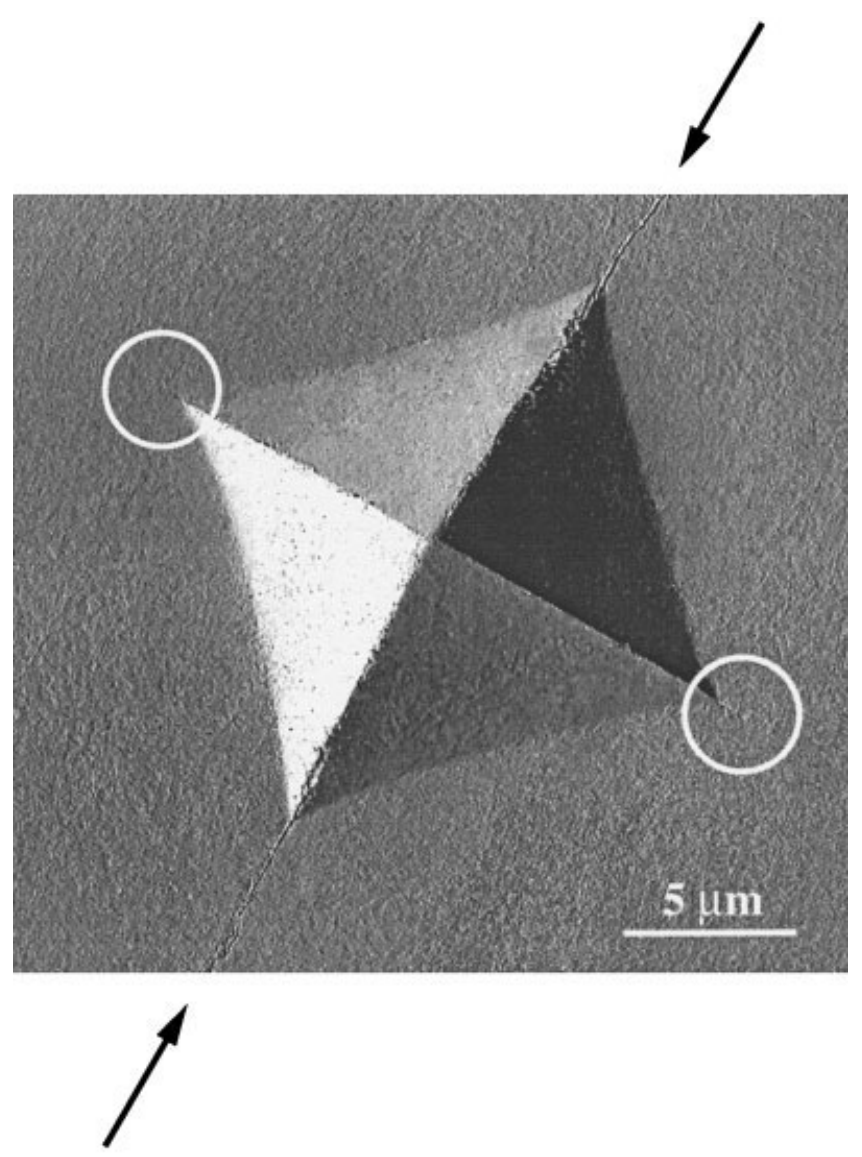

Figure 2. Atomic force micrograph of Vickers indent at load $P=10$ $N$, after failure in bilayer test at stress $S=597 \mathrm{MPa}$ after $n=1.7 \times$ $10^{5}$ cycles at $10 \mathrm{~Hz}$. Arrows indicate failure path, circles indicate emergence of small cracks at remaining indentation corners.

points below this range represent breaks from natural flaws. The box on the left axis represents mean and standard deviation bounds for unindented specimens. The data for indentation-site failures show a monotonically increasing strength $S$ with decreasing load $P$, despite a switch from Vickers to Berkovich indenters at $P=1 \mathrm{~N}$. The solid line through these data is a force fit according to the conventional strength relation $S \propto P^{-1 / 3}$ for indentations with well-developed radial cracks. ${ }^{1,33}$ Strong significance should not be attached to any goodness of this fit in the subthreshold region below $P=10$ $N$, where no surface cracks are visible.

A plot of maximum stress $S$ as a function of number of flexure cycles $n$ is shown in Figure 4, for specimens containing indentations at loads $P=0.1,1$, and $10 N$. Again, failures from indentation sites are represented by filled symbols, failure from natural flaws by unfilled symbols. Also included are control data for polished specimens without indentations. Solid lines are simple spline fits to the data. Failures now occur from even the smallest indentations, that is, at $P=0.1$ $N$ and $1 \mathrm{~N}$, after some 100 cycles or more, suggesting incipient microcrack evolution within the residual plastic contact zones. At $P=1 \mathrm{~N}$, the data falloff is somewhat less pronounced, suggesting some steady state in the microcrack

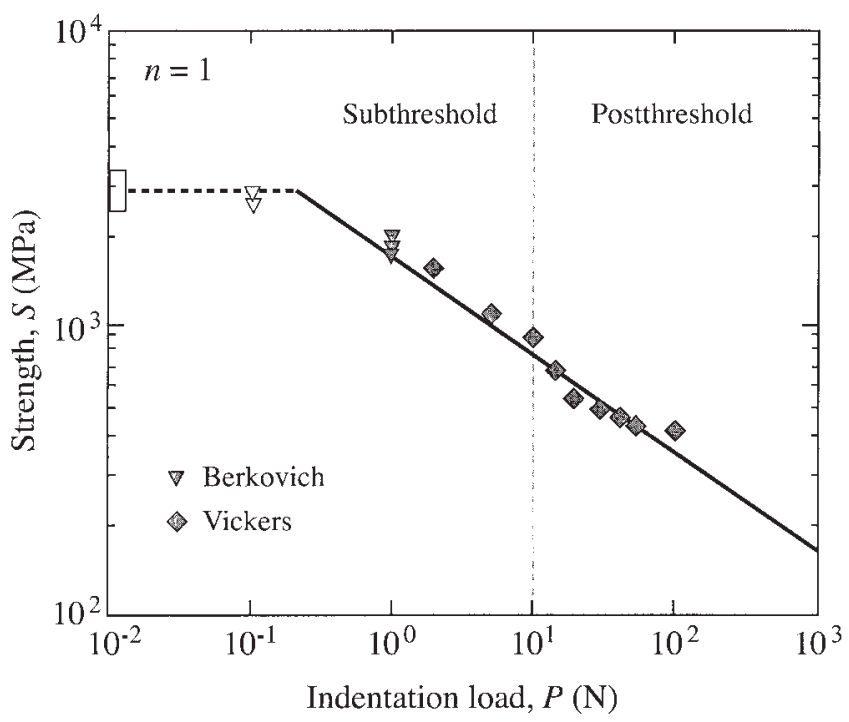

Figure 3. Single-cycle strength as function of indentation load for Y-TZP. Data shown for Vickers and Berkovich indenters. Filled symbols represent breaks from indent sites, unfilled symbols breaks from natural flaws. Solid line is fit to data in accordance with conventional indentation fracture relation $S P^{1 / 3}=$ constant. Horizontal dashed line is natural flaw cutoff.

evolution. At $P=10 \mathrm{~N}$, degradation accelerates again after some 10 cycles, and minute radial cracks appear at the indentation corners (Figure 2), indicative of some microcrack coalescence. The data points with arrows represent runouts, and may signal the existence of strength thresholds. ${ }^{34}$

Figure 5 shows some monotonic loading (constant stressing rate) data for two of the indentation loads, $P=0.1 \mathrm{~N}$ and $10 \mathrm{~N}$, represented in Figure 4. These data may be compared

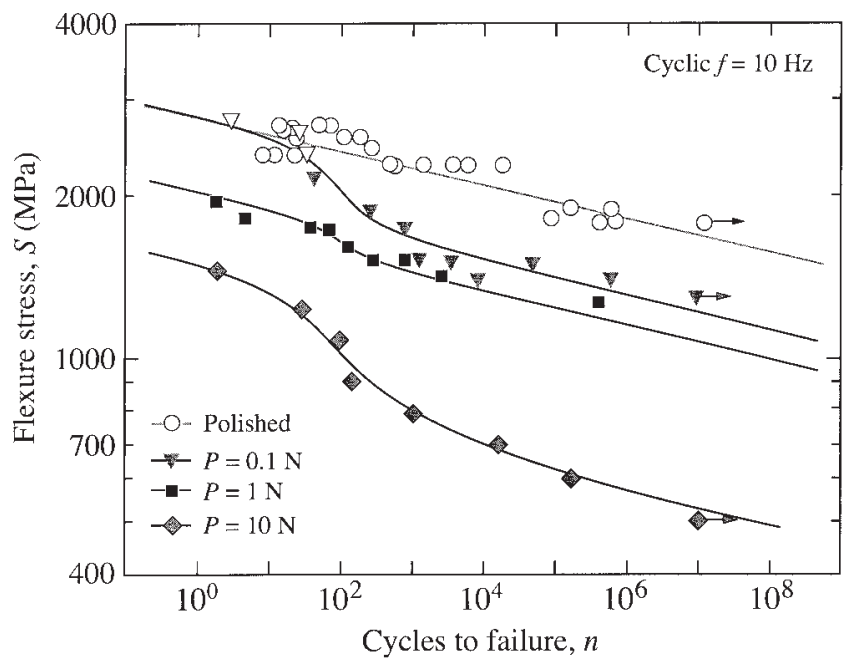

Figure 4. Tensile stress $S$ as function of number of cycles $n$ to failure in bilayer test at $f=10 \mathrm{~Hz}$ for ceramic plates containing lower-surface indentation flaws at specified loads. Results for as-polished surfaces serve as control (data from Zhang and colleagues ${ }^{17,18}$ ). Solid line through data for polished surface is linear best fit, in accordance with a purely slow crack growth model. Other solid lines are smoothed curves through the indentation data. 


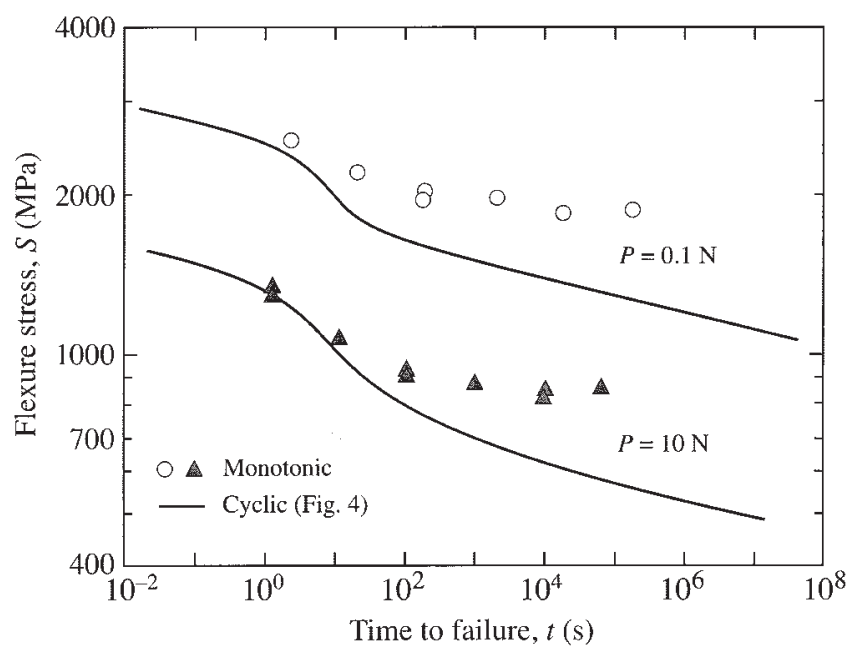

Figure 5. Stress $S$ as function of time $t$ to failure in bilayer test in monotonic (constant stressing rate) loading for ceramic containing lower-surface indentation flaws at $P=0.1 \mathrm{~N}$ and $10 \mathrm{~N}$. Solid lines are fits to cyclic data for sharp-indenter damage from Figure 4 at the corresponding loads, using relation $t=n / f$ to convert the data.

with the solid lines from the corresponding cyclic data fits in Figure 4 . The strength degradation is clearly stronger in the cyclic than the monotonic data, confirming a substantial mechanical degradation contribution to the fatigue.

To place the indentation flaw results in some practical perspective, in Figure 6 we compare the present results with some data from previous studies on specimens containing a quasiplastic zone from a tungsten carbide sphere of indenter of radius $1.98 \mathrm{~mm}$ at load $3000 \mathrm{~N}^{17}$ plus sandblast damage with $50 \mu \mathrm{m} \mathrm{Al}{ }_{2} \mathrm{O}_{3}$ particles. ${ }^{18}$ The quasiplastic data represent the kind of damage that might be incurred from some form of blunt trauma in a total hip replacement (e.g., surgeon's orthopedic hammer); the sandblast data represent the damage from a typical dental technician's preparation of a dental crown. The solid lines from Figure 4 corresponding to 0.1 and $1 \mathrm{~N}$ indents are seen to provide bounds for these two kinds of damage, thereby quantifying the severity of each damage mode.

\section{DISCUSSION}

This study has demonstrated the high fatigue sensitivity of Y-TZP ceramic to sharp-indenter damage in cyclic flexural stressing. Strength losses amounting to almost an order of magnitude may be incurred from such damage over extended periods (Figure 4). The damage zones themselves may be imperceptibly small, on the order of micrometers at sub- $N-$ scale loads (Figure 2). In this context, Y-TZP, with its limited toughness, must be regarded as a relatively brittle zirconia, seemingly strong by general ceramic standards yet ever susceptible to severe strength losses from spurious contact with microscale particulates that impinge on the ceramic surface or become entrapped between articulating surfaces. ${ }^{31,35}$ Damage from sandblasting treatments ordinarily used to prepare crown cementation surfaces appears to be equivalent to $\sim 1$ $N$ indentation contacts (Figure 6). Given the stringent loading and cycling conditions that characterize biomechanical prostheses, it becomes clear that due effort should be exercised to maintain a particulate-free environment during the various phases of component fabrication, handling, and ensuing function. Strength losses can be further exacerbated by hydrothermal degradation of the Y-TZP during aging at moderate temperatures (e.g., during sterilization). ${ }^{18}$

The sensitivity of Y-TZP to small-scale contact damage raises the issue of the flaws responsible for failure. For pristine plates with well-polished surfaces, the flaws are associated with the microstructure of the material. Because the intrinsic strength of the Y-TZP is high, in excess of $1 \mathrm{GPa}$, these flaws are necessarily small, on the scale of the grain size $\approx 0.5 \mu \mathrm{m}$. The presence of water in the atmosphere facilitates extension of those flaws near the specimen tensile surface into microcracks, via a slow crack growth mechanism. ${ }^{17,18}$ Sharp contacts introduce local quasiplasticity, ${ }^{7}$ which provides additional, locally intense driving forces on the intrinsic microcrack sources. ${ }^{17,18,32,36,37}$ The microcracks within the damage zone are especially susceptible to degradation by reverse frictional sliding at their internal interfaces, resulting in accelerated strength loss during cycling (Figure 5). ${ }^{8,12,13,38-40}$ The importance of residual contact stresses in the microcrack evolution process is brought home by the fact that a sharp (diamond pyramid) contact at $P=0.1 \mathrm{~N}$ is as deleterious as a blunt (1.98 $\mathrm{mm}$ radius $\mathrm{WC}$ sphere) contact at $3000 N$ (Figure 6). In the blunt contact, the much larger quasiplastic zone may contain many more, but still separate, microcracks; whereas the sharp indenter, although encompassing a smaller deformation zone, concentrates the stresses much more strongly, albeit on a much smaller number of microcracks. At higher sharp-indenter loads where the

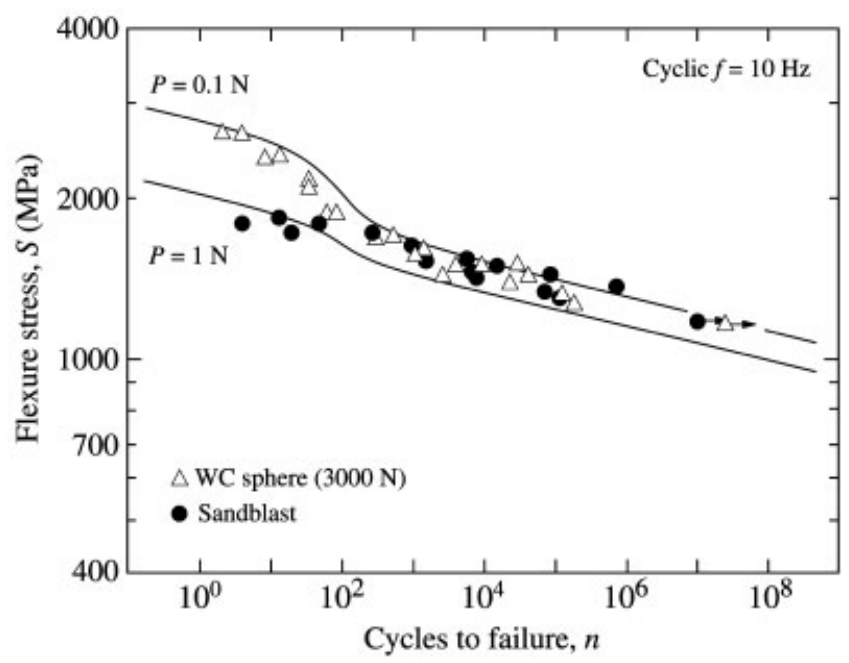

Figure 6. Stress $S$ as function of number of cycles $n$ to failure in bilayer test at $f=10 \mathrm{~Hz}$ for ceramic plates containing lower-surface quasiplastic damage from a WC sphere at $3000 \mathrm{~N}$ and sandblast damage (data from Zhang and colleagues ${ }^{17,18}$ ). Solid lines are fits to cyclic data for sharp-indenter damage at $P=0.1 \mathrm{~N}$ and $1 \mathrm{~N}$ from Figure 4. 
strength degradation becomes more pronounced, for example, $P=10 \mathrm{~N}$ in Figure 4, the microcracks begin to interact and coalesce as cycling progresses, as evidenced by the appearance of corner cracks in Figure 2. For even larger indenter loads, that is, $P=100 \mathrm{~N}$ (Figure 2), where full-scale radial cracks develop, slow crack growth is expected once more to become the dominant fatigue mechanism. ${ }^{34}$

Y-TZP specimens were generously supplied by Norton Desmarquest.

\section{REFERENCES}

1. Lawn BR, Evans AG, Marshall DB. Elastic/plastic indentation damage in ceramics: the median/radial crack system. J Am Ceram Soc 1980;63:574-581.

2. Reece M, Guiu F, Sammur MFR. Cyclic fatigue crack propagation in alumina under direct tension-compression loading of high-purity alumina in fluid environments. J Am Ceram Soc 1989;72:348-352.

3. Guiu F, Reece M, Vaughan DAJ. Cyclic fatigue of ceramics. J Mater Sci 1991;26:3275-3286.

4. Reece M, Guiu F. Indentation fatigue of high-purity alumina in fluid environments. J Am Ceram Soc 1991;74:148-154.

5. Guiberteau F, Padture NP, Cai H, Lawn BR. Indentation fatigue: a simple cyclic Hertzian test for measuring damage accumulation in polycrystalline ceramics. Philos Mag 1993;A68: 1003-1016.

6. Cai H, Kalceff MAS, Hooks BM, Lawn BR, Chyung K. Cyclic fatigue of a mica-containing glass-ceramic at Hertzian contacts. J Mater Res 1994;9:2654-2661.

7. Lawn BR, Padture NP, Cai H, Guiberteau F. Making ceramics ductile. Science 1994;263:1114-1116.

8. Padture NP, Lawn BR. Contact fatigue of a silicon carbide with a heterogeneous grain structure. J Am Ceram Soc 1995;78: 1431-1438.

9. Padture NP, Lawn BR. Fatigue in ceramics with interconnecting weak interfaces: a study using cyclic Hertzian contacts. Acta Metall 1995;43:1609-1617.

10. Pajares A, Wei L, Lawn BR, Marshall DB. Damage accumulation and cyclic fatigue in Mg-PSZ at Hertzian contacts. J Mater Res 1995;10:2613-2625.

11. Peterson IM, Pajares A, Lawn BR, Thompson VP, Rekow ED. Mechanical characterization of dental ceramics using Hertzian contacts. J Dent Res 1998;77:589-602.

12. Lee SK, Lawn BR. Contact fatigue in silicon nitride. J Am Ceram Soc 1999;82:1281-1288.

13. Jung Y-G, Peterson IM, Kim DK, Lawn BR. Lifetime-limiting strength degradation from contact fatigue in dental ceramics. J Dent Res 2000;79:722-731.

14. Lee KS, Jung Y-G, Peterson IM, Lawn BR, Kim DK, Lee SK. Model for cyclic fatigue of quasiplastic ceramics in contact with spheres. J Am Ceram Soc 2000;83:2255-2262.

15. Lawn BR, Deng Y, Miranda P, Pajares A, Chai H, Kim DK. Overview: damage in brittle layer structures from concentrated loads. J Mater Res 2002;17:3019-3036.

16. Lawn BR, Pajares A, Zhang Y, Deng Y, Polack M, Lloyd IK, et al. Materials design in the performance of all-cCeramic crowns. Biomaterials 2004;25:2885-2892.

17. Zhang Y, Pajares A, Lawn BR. Fatigue and damage tolerance of Y-TZP ceramics in layered biomechanical systems. J Biomed Mater Res 2004;71B:166-171.
18. Zhang Y, Lawn BR, Rekow ED, Thompson VP. Effect of sandblasting on the long-term strength of dental ceramics. J Biomed Mater Res 2004;71B:381-386.

19. Willmann G. Ceramic femoral heads for total hip arthroplasty. Adv Eng Mater 2000;2:114-122.

20. Willmann G. Improving bearing surfaces of artificial joints. Adv Eng Mater 2001;3:135-141.

21. Ritchie RO. Mechanisms of fatigue crack propagation in ductile and brittle solids. Int J Fract 1998;100:55-83.

22. Kelly JR. Ceramics in restorative and prosthetic dentistry. Ann Rev Mater Sci 1997;27:443-468.

23. Kelly JR. Clinically relevant approach to failure testing of all-ceramic restorations. J Prosthet Dent 1999;81:652-661.

24. Lawn BR, Deng Y, Thompson VP. Use of contact testing in the characterization and design of all-ceramic crown-like layer structures: a review. J Prosthet Dent 2001;86:495-510.

25. Zhang Y, Lawn BR. Long-term strength of ceramics for biomedical Applications. J Biomed Mater Res 2004;69B:166-172.

26. Lawn BR, Marshall DB. Hardness, toughness, and brittleness: an indentation analysis. J Am Ceram Soc 1979;62:347-350.

27. Deng Y, Lawn BR, Lloyd IK. Characterization of damage modes in dental ceramic bilayer structures. J Biomed Mater Res 2002;63B:137-145.

28. Deng Y, Miranda P, Pajares A, Lawn BR. Fracture of ceramic/ ceramic/polymer trilayers for biomechanical applications. J Biomed Mater Res 2003;67A:828-833.

29. Chai H, Lawn BR, Wuttiphan S. Fracture modes in brittle coatings with large interlayer modulus mismatch. J Mater Res 1999;14:3805-3817.

30. Miranda P, Pajares A, Guiberteau F, Deng Y, Lawn BR. Designing damage-resistant brittle-coating structures: I. Bilayers. Acta Mater 2003;51:4347-4356.

31. Readey MJ, McCallen CL, McNamara P, Lawn BR. Correlations between flaw tolerance and reliability in zirconia. J Mater Sci 1993;28:6748-6752.

32. Cook RF, Braun LM, Cannon WR. Trapped cracks at indentations: I. Experiments on yttria-tetragonal zirconia polycrystals. J Mater Sci 1994;29:2133-2142.

33. Marshall DB, Lawn BR, Chantikul P. Residual stress effects in sharp-contact cracking: II. Strength degradation. J Mater Sci 1979;14:2225-2235.

34. Lathabai S, Mai Y-W, Lawn BR. Cyclic fatigue behavior of an alumina ceramic with crack-resistance curves. J Am Ceram Soc 1989;72:1760-1763.

35. Lee SK, Tandon R, Readey MJ, Lawn BR. Scratch damage in zirconia ceramics. J Am Ceram Soc 2000;83:1428-1432.

36. Kosmac T, Oblak C, Jevnikar P, Funduk N, Marion L. The effect of surface grinding and sandblasting on flexural strength and reliability of Y-TZP zirconia ceramic. Dent Mater 1999;15: 426-433.

37. Kosmac T, Oblak C, Jevnikar P, Funduk N, Marion L. Strength and reliability of surface treated Y-TZP dental ceramics. J Biomed Mater Res 2000;53:304-313.

38. Pajares A, Guiberteau F, Lawn BR, Lathabai S. Hertzian contact damage in magnesia-partially-stabilized zirconia. J Am Ceram Soc 1995;78:1083-1086.

39. Lawn BR, Kim DK, Lee SK, Jung Y-G, Peterson IM. Cyclic contact fatigue of brittle ceramics. In: Wu XR, Wang ZG, editors. The Seventh International Fatigue Conference, Fatigue 99. Beijing; Higher Education Press: 1999. p 69-80.

40. Kim DK, Jung Y-G, Peterson IM, Lawn BR. Cyclic fatigue of intrinsically brittle ceramics in contact with spheres. Acta Mater 1999;47:4711Wu XR and Wang ZG, editor. 4725. 